Gazi University
Journal of Science
PART A: ENGINEERING AND INNOVATION
http://dergipark.org.tr/gujsa

\title{
Determination of the Bed Hydrodynamics by MFIX-PIC in the Biomass Gasification Process of Circulating Fluidized Bed
}

\author{
${ }^{I}$ Gazi University, Department of Mechanical Engineering \\ ${ }^{2}$ Doğuş University, Department of Mechanical Engineering
}

Yelda ALTINSOY ${ }^{1(D)}$, Ahmet $\mathrm{KEÇECI}^{2}$ (D), Hüseyin TOPAL

\begin{tabular}{ll}
\hline Keywords & Abstract \\
\hline Fluidized Bed & In this study, it was aimed to control the formation of flow regimes planned to be in the gasification \\
pydrodynamic & $\begin{array}{l}\text { process on the model, and the hydrodynamic structure of the circulating fluidized bed gasifier was } \\
\text { obtructure }\end{array}$ \\
and hydrodynamic modeling was performed by entering the system dimensions that were calculated \\
analytically. Because it is a necessary condition from the point of view of the chemical reaction to ensure \\
the fluid bed regime of the gasifier, which is designated as a solid model, is a necessary condition. For \\
this reason, the system whose geometry was determined and semi-empirical modeling was performed \\
wPas modeled under previously determined operating conditions using the PIC (Eulerian-Lagrangian) \\
model in the MFIX package program. \\
In this technique, while fluid behavior is resolved by the Euler structure, particle behaviour is considered \\
by the Lagrangian structure. The numeral effects are in great arrangement with the empiric datum \\
showing that MFIX-PIC methods are reasonable among concentrated gas-solid network simulation. The \\
primary characteristics of gas-solid streams in CFB are qualitatively determined by an ordinary annular \\
flux form inside the main bed. The pressure inclination formed in the gas phase inside the lower and \\
upper zones of the CFB bed column indicated turbulent and irregular gas-solid streams in lower and \\
upper zones. The increased superficial gas velocity conducts to a further dissymmetrical gas axial \\
velocity model, which shows improved effect in the recycling frame for gas homogeneity due to the over \\
gas velocity. The superficial gas velocity obtained as a result of the MFIX-PIC modelling was found to \\
be 7m/s for $100 \mathrm{~kW}$ th gas yield in the gasifier. The superficial gas velocity is the most basic parameter \\
to be used both in the experimental parameter and in the thermochemical simulation.
\end{tabular}

Cite

Altınsoy, Y., Keçeci, A., \& Topal, H. (20**). Determination of the bed hydrodynamics by MFIX-PIC in the biomass gasification process of circulating fluidized bed. GU J Sci, Part A, 8(4), 551-569.

\begin{tabular}{lrl}
\hline Author ID (ORCID Number) & Article Process \\
\hline Y. Altınsoy, 0000-0002-5277-6981 & Submission Date & 30.11 .2021 \\
A. Keçeci, 0000-0001-6502-3172 & Revision Date & 22.12 .2021 \\
H. Topal, 0000-0001-7406-4398 & Accepted Date & 30.12 .2021 \\
& Published Date & 31.12 .2021 \\
\hline
\end{tabular}

\section{INTRODUCTION}

Especially in energy sector, CFBs are extensively used in the several industrial application like, refinery, chemical, metal and environmental industries because of the transportation profits such as momentum, heat and mass transports parameters (Kunii \& Levenspiel, 1991) However, due to the complicated CFB hydrodynamics structure, a comprehensive numerical and experimental investigation is needed. However, a detailed understanding of hydrodynamics structure and mass transport methods for gas-solid is needed to promote fluidized bed design, optimization and operation, especially when considering gasification. However, CFB in particular is intense sensitive gas/solid frameworks which carry out complex chemical reactions. At the same time, the fact that it provides high solid velocity, dense interaction between particles and significant heat and mass transfer makes it more important (Zhong et al., 2016). Because of numerical difficulties and intricacies in application estimates, fluidized bed studies are often qualified to a small-scale setup. Knowledge required for a minor size gasifiers are utilized to evaluate the hydrodynamic structure of a major scale gasifier. 
Also, the gas/solid flows occurring in a major-scale gasifier are quite dissimilar compared in a minor-scale gasifier (Squires, 1982). Therefore, such an approach has not been found appropriate in the literature (Verma et al., 2015).

With the advancement of computational algorithms in recent years, numerical simulation modeling has become a powerful tool, especially in gas-solid two-phase flows (Gu et al., 2018; Liu \& van Wachem, 2019; Stroh et al., 2019). It is important to study fluidized beds large enough to be able to solve industrial-scale problems using modeling. There are many studies on coarse grain models in CFD modeling studies. Because it is very important to enable modeling of gas/solid flows in large scale systems. Today, CFD studies are successfully used to obtain gas-solid hydrodynamic structure of fluidized beds. In order to model gas/solid flows [8] EulerLagrange Computational Fluid Dynamics-Discrete Element Model (CFD-DEM) (Tsuji et al., 1993; Deen et al., 2007) is based on the determination of micro and macro structural properties with a multi-scale approach. These two approaches have shown to give more accurate results for gas/solid flows. Usually, CFD approachment is separated to two types as E-E technique and E-L technique, which are based on solid phase processing. One of them considers it as a continuum in which the motion of the solid phase is solved by Euler's method. This approach is widely used to simulate large-scale CFBs because of its less precise resolution (Zhang et al., 2010; Nikolopoulos et al., 2013; Hamidouche et al., 2019).

However, the Eulerian-Eulerian method does not provide information on particle sizes for the solid phase and does not show the multiple distribution of the particle size distribution. The Eulerian-Lagrange approach, which is applied based on inter particle collision, has also found applications in more fields of CFD by combining DEM and multiphase particle in cell method (MP-PIC) methods (Alobaid, 2015). In the DEM technique, each particle is tracked and wall/particle/particle impact are resolved in the soft sphere impact technique (Cundall \& Strack, 1979). However, studies in the literature on this subject are very few, especially for CFB simulations (Luo et al., 2015; Wang et al., 2017a, b; Xu et al., 2018; Yang et al., 2019). Comparing the MP-PIC modeling method with DEM, it uses a renewed method to simulate particle/particle impact. The purpose of this method is to reduce accounting costs. In other words, collecting particles with the same properties in a digital parcel provides a significant reduction in the number of particles that need to be monitored.

Also, solid compression stress is included in the MP-PIC technique to simulate information about inter particle impact. The weakness of the MP-PIC method lies in the simplification of the particle collision method, causing several particle scale features to be technically not accounted for in the simulation. However, in practice, in large-scale CFB simulations, the parameters of the particles, such as rotation and/or shape, can be neglected and supposed to be spherical (Shi et al., 2015; Liu et al., 2015; 2018). The Particle in Cell (PIC) approach has received great attention in industrial applications with gas-solid multicomponent flows. The methodology was first proposed by Andrews \& O'Rourke (1996) for one-dimensional systems and extended to three-dimensional systems by Snider (2001).

In the PIC process (Snider, 2001; O'Rourke et al., 2009; O'Rourke \& Snider, 2012; 2014), the gas phase is processed using an Euler framework, while the particles are grouped into computational plots and tracked as separate entities. Also, gas-solid streams, Andrews \& O'Rourke (1996) proposed "Multiphase particle in cell" (MP-PIC) touch, that is the parcel touch and is widespread carried out in grain flow. This approach has also been widely used by Snider (2001), O'Rourke et al. (2009) and O'Rourke \& Snider (2010), for granular flow. In particular, without solving particle collisions or governing Newtonian mechanics in any way, the PIC model generates a clustered solid stress momentum source term that directly affects the velocity of local solids (Snider, 2001). He defines this source term with a friction stress model, the friction stress model being driven by an assessment of the local solids volume ratio gradient and average area quantities. This statement implies that the model application is algebraic and thus computationally efficient. As a result, the PIC model can offer computational predictions for large industrial applications suitable for watchable wall time. Besides the friction stress model, the PIC can support auxiliary models (for example, a collision stress model, and wall friction models) that can contribute to the fidelity of the results. As with all combined computational fluid dynamics (CFD) simulations, these utility models will add time to the solution (Clarke \& Musser, 2020). 
Collisions between particles within parcels are not resolved but inter particle collisions are modeled using the stress term. Stress expression Auzerias et al. (1988) reported. Also, there are various numerical parameters used in conditional expressions within PIC routines, and their effects on results have not yet been measured. Despite these shortcomings, the PIC methodology has proven to model gas-solid systems quite well. While not as accurate as the discrete element modeling (DEM) approach, significant acceleration can be achieved using MFiX-PIC for large-scale systems. Instead of directly monitoring collisions between particles, PIC uses an ordinary "particle pressure" approach to avoid particles away being tightly wrapped. Patankar \& Joseph (2001) investigated an Euler-Lagrange computational simulation (LNS) draft for particle stream and displayed which the parcel approach could catch the fundamental streams properties. However, this method is applicable where collisions occurring in the flow do not predominate, especially in dilute flow. In a model developed by Sakai \& Koshizuka (2009), a coarse-grained model was determined by considering friction force and contact force. In this model, 3D piston flow is accurately modeled on a horizontal pipeline. However, the small number of calculated particles limited the system. However, in the DEM modeling is studied by Mokhtar et al. (2012), the similar particle assembly (SPA) model proposed for large-scale systems was verified. In Mokhtar et al. (2012) study, it is noteworthy that particles with the same properties (physical, chemical) are represented by a single particle. Bulk volume fractions were found to be independent of grain size (Bierwisch et al., 2009). It is important to know that second study is limited to dilute particulate systems that dual impacts occur only. It is unclear whether scaling applies in moderate to intense regimens.

Moreover, numerous modelling studies have demonstrated where the MP-PIC technique could evaluate intense gas-solid stream in major-scale CFBs using fairly great particle counts as accurately as they actually are. Jiang et al. (2014) investigated the gas-solid streams hydrodynamic structure of CFB which has six cyclone and determined that the computational consequent is similar as the ECT measurements. Wang et al. (2014) and Jiang et al. (2014) investigated the effect of simulating datas on the evaluation unity of the MP-PIC technique in his study. Liu et al. (2017) aimed to improve the solid circulation ratio for gas-solid stream in a binary CFB gasifier. Gu et al. (2018) studied parameters that may be important in CFB in a dual gasifier. As a result, the advantage of MFIX-PIC modeling compares to other modeling techniques can be explained as follows. The MFiX-PIC is best suited for industrial size and semi-intensive systems using multiphase flow simulations where precise parameters are paramount. The method mostly uses statistical averaging technique so that simulations can be run quickly and have minimal particle load.

\section{MODELING STUDIES}

This study constitutes the first step of modeling in the CFB gasifier. In order to determine the gas-solid contact properties required for the gasification mechanism, the MFIX open source package program was used. Numerical solution was performed with the particle-in-cell (PIC) model. For a highly efficient gasification process, it is necessary to create the necessary conditions, to fully understand the bed hydrodynamic structure and to determine the operating parameters under these hydrodynamic conditions.

The experimental system in which the biomass gasification study will be carried out is given in Figure 1. In this study, the solid-gas flow properties were numerically investigated as the first step in the circulating fluidized bed gasifier modeling. Fluid bed measurements were taken from the experimental system.

\subsection{Overview of MFIX-PIC}

The MFIX-PIC method was first proposed by Andrews \& O'Rourke (1996) to see dense particle flows. Andrews \& O'Rourke (1996) used the mass and momentum conservation equations accepted in TFM (Two Fluid Method) for gas phase motion. For the solid phase motion, it was solved by using Newton's second law of motion, by tracing the particles with the same properties on separate graphs. The MP-PIC model cannot resolve collisions directly. The Eulerian-Lagrange (E-L) method defines the gas phase as the continuum and the solid phase as the sum of the individual elements. The continuity equation is used for the gas phase, while the volume-averaged convection equations are used to solve the momentum balance. The MFIX-PIC technique's equations are given below. 
Continuity equation for gas phase:

$$
\frac{\partial}{\partial t}\left(\varepsilon_{g} \rho_{g}\right)+\nabla \cdot\left(\varepsilon_{g} \rho_{g} \vec{u}_{g}\right)=0
$$

Gas phase momentum equation:

$$
\frac{\partial}{\partial t}\left(\varepsilon_{g} \rho_{g} \vec{u}_{g}\right)+\nabla \cdot\left(\varepsilon_{g} \rho_{g} \vec{u}_{g} \vec{u}_{g}\right)=-\varepsilon_{g} \nabla p+\nabla \cdot\left(\overline{\bar{\tau}}_{g}\right)+\varepsilon_{g} \rho_{g} \vec{g}-\sum n_{p} \frac{V_{p}}{V_{c e l l}} \beta_{p}\left(\vec{U}_{g}\left(\vec{x}_{p}-\vec{U}_{p}\right)\right.
$$

Here;

Sub-symbol $g$ symbolizes the gas phase, $n \_T$, is liquid cell parcel number and $n \_p$,is particles per parcel number. V_p and V_(cell) are particle and liquid cell volumes, one by one. $\beta p$ is friction coefficient, $\mathrm{U}_{-} \mathrm{g}(\mathrm{x}$ $\left.{ }_{-} \mathrm{p}\right)$ is the superficial gas velocity at the parcel position, $\mathrm{x}_{-} \mathrm{p}$ and $\mathrm{U}_{-}{ }_{-} \mathrm{p}$ parcel velocity $\tau_{-}{ }_{\mathrm{g}} \mathrm{g}$ is stress tensor of gas phase :

$$
\begin{aligned}
& \overline{\bar{\tau}}_{s}=2 \mu \overline{\bar{S}}_{g} \\
& \overline{\bar{S}}_{g}=\frac{1}{2}\left[\nabla \vec{U}_{g}+\left(\nabla \vec{U}_{g}\right)^{T}\right]-\frac{1}{3} \nabla \vec{U}_{g} \vec{I}
\end{aligned}
$$

Parcel motion equations

$$
\begin{aligned}
& \frac{d \vec{x}_{p}}{d t}=\vec{U}_{p} \\
& \frac{d \vec{U}_{p}}{d t}=\nabla \mathrm{p}-F_{c} \cdot \vec{g}+\frac{\beta_{g}}{\rho_{s}}\left(\vec{U}_{g}\left(\vec{x}_{p}\right)-\vec{U}_{g}\right)
\end{aligned}
$$

Here;

When the symbol "s" symbolizes solid phase, F_c interaction force of particle.

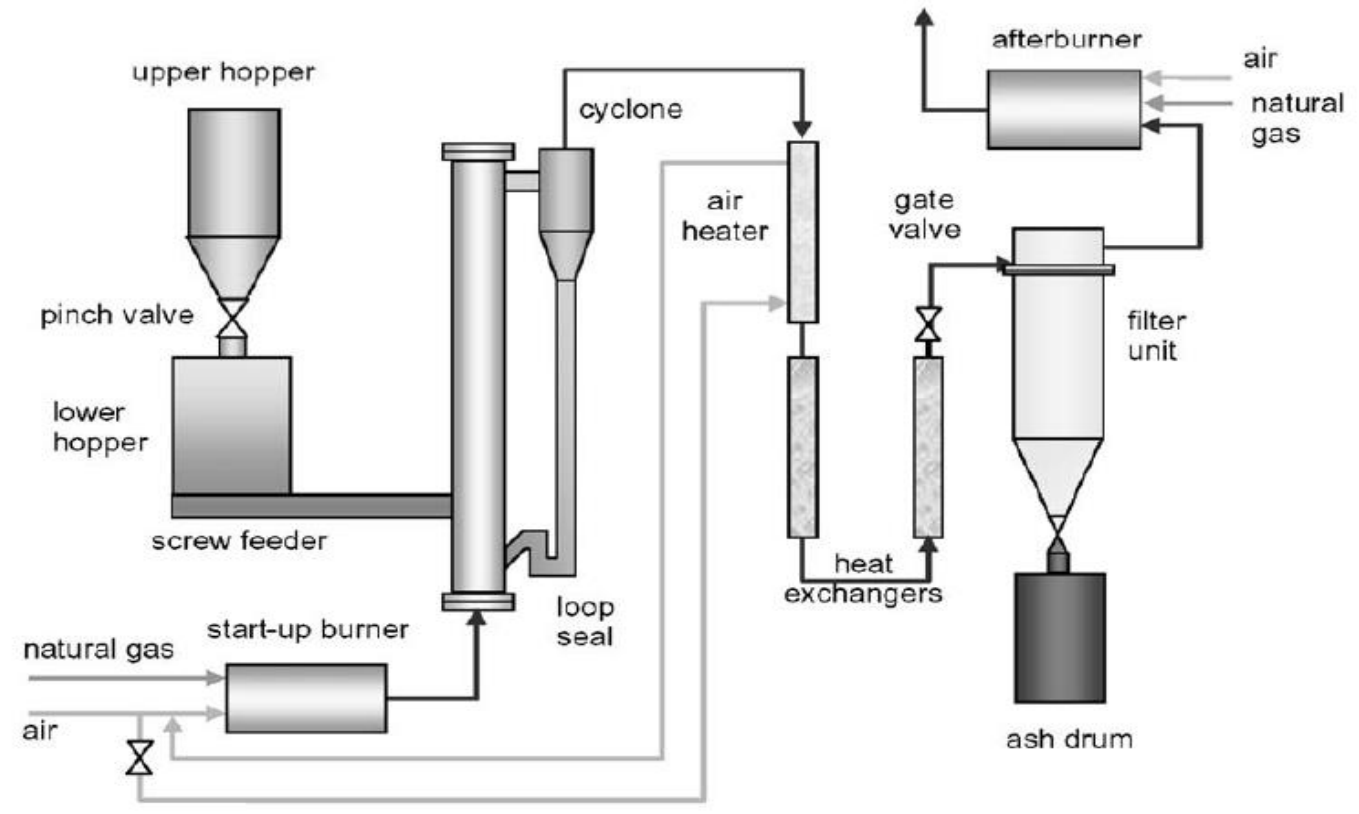

Figure 1. Experimental Setup of CFB 


\subsection{Gas-Solid Drag Model}

In order to predict gas/solid flows in CFBs, the frictional force between gas and solid must be taken into account. The Gidaspow drag model (Gidaspow, 1994) is a widely used model. In this model, a model based on mono-dispersed particles was determined. In the simulation of gas/solid flows, the need for remodeling has emerged, especially for DEM poly disperse particles (Zhang et al., 2017, Lu et al., 2019). However, in many studies (Liu et al., 2015; Kallio et al., 2015; Thapa et al., 2016; Ma et al., 2017) mono-disperse drift model has been used in poly-disperse systems and very positive results have been obtained. In this study, the Gidaspow drag model, Wen \& Yu (1966) and Ergun model (1952) were combined and used. The formulation of the Gidaspow drag model used in this study is as follows (Ding \& Gidaspow, 1990),

$$
\begin{aligned}
& \beta_{g m}=\left\{\begin{array}{cc}
\frac{3}{4} C_{D} \frac{\rho_{g} \varepsilon_{g} \varepsilon_{m}\left|U_{g}-U_{m}\right|}{\rho_{p} d_{p}} \varepsilon_{g}^{-2.65} & \varepsilon_{g} \geq 0.8 \\
\frac{150 \varepsilon_{s}\left(1-\varepsilon_{g}\right) \mu_{g}}{\varepsilon_{g} d_{p m}^{2}}+\frac{1.75 \rho_{g} \varepsilon_{g}\left|U_{g}-U_{m}\right|}{d_{p m}} & \varepsilon_{g} \geq 0.8
\end{array}\right. \\
& C_{D}=\left\{\begin{array}{cc}
24 / R_{e}\left(1+R e^{0.687}\right) & R e<1000 \\
0.44 & R e \geq 1000
\end{array}\right. \\
& \operatorname{Re}=\frac{\rho_{g} \varepsilon_{g}\left|U_{g}-U_{m}\right| d_{p m}}{\mu_{g}}
\end{aligned}
$$

\subsection{Modeling Parameters}

Method: Particle-In-Cell (PIC)

Solid-Gas Drag Model: Gidaspow

Lattice cell size:

$\mathrm{X}: 1.24 \times 10-2 \mathrm{~m}$,

$\mathrm{H}: 1.28 \times 10-2 \mathrm{~m}$,

$\mathrm{Z}: 1.27 \times 10-2 \mathrm{~m}$

(Cell sizes in the range of 20-30 times the particle diameter are compatible with the solutions used in the literature.)

\section{Numerical Solution Parameters:}

- Maximum 500 iterations for each time step

-Implicit Euler for temporal discretization, Superbee scheme for dimensional discretization

The simulation, which was run for -10 seconds, was started with $1.0 \times 10-4 \mathrm{~s}$ time step, and it was adjusted depending on the CFL value in the range of $1.0 \times 10^{-7}-1.0 \times 10^{-2} \mathrm{~s}$ time step. A time step factor of 0.9 is used for the time step adjustment.

\subsection{Parameters required for simulation}

In this study, the MFIX-PIC package program was used for the numerical solution in the experimentally created circulating fluidized bed (CFB). The circulating fluidized bed is composed of riser, cyclone, drop pipe, loop seal. 
The three-dimensional geometry diagram of the bed and the lattice cells obtained as a result of the modeling are shown in Figure 2. The main bearing height is $5,500 \mathrm{~m}$, the main bearing diameter and the drop pipe diameter are $0.100 \mathrm{~m}$ and $0.076 \mathrm{~m}$, respectively. Superficial gas velocity $(\mathrm{Ug})$ is $7.0 \mathrm{~m} / \mathrm{s}$ from the distributor located under the main bearing.

Aeration mass flow rate (Qr) is given as $0.04 \mathrm{~kg} / \mathrm{s}$ loop seal, which aims to transport particles from the fall pipe to the bearing column. At the same time, the other purpose of the aeration mass flow is to provide the returning solid flow to the cyclone bed by providing pressure balance. The CFB matter is silica sand using an average dp $0.530 \mathrm{~mm}(530 \mu \mathrm{m})$ and a concentration of $2500 \mathrm{~kg} / \mathrm{m} 3$ belonging to Geldart group B particles. The grid cells in the model were first created with Cartesian grid cells. Afterwards, the solid model created with the CAD program to determine the wall conditions was converted into solution networks with the cutcell method.

Boundary conditions must be set carefully before calculation. Specifically, the initial air inlet is defined as a unique mass flow limiting condition, while vent port inlet (return zone gas inlet) is defined as an main line limiting condition (point source). The pressure output limiting conditions are selected in which the cyclone outlet. Non-slip limiting condition are chosen for all walls are set. Solid matter primarily gather in the main column and loop seal by a space portion of 0.5 .

$1.0 \times 10^{-4} \mathrm{~s}$ is an initial time step which set in the current modelling, and the time step is being automatically set throughout sum lean the Courant Friedrichs Lewy number (CFL). Volume fraction of closed packing is specified as 0.55 . Another considerable modelling datas are shown in Table 1.
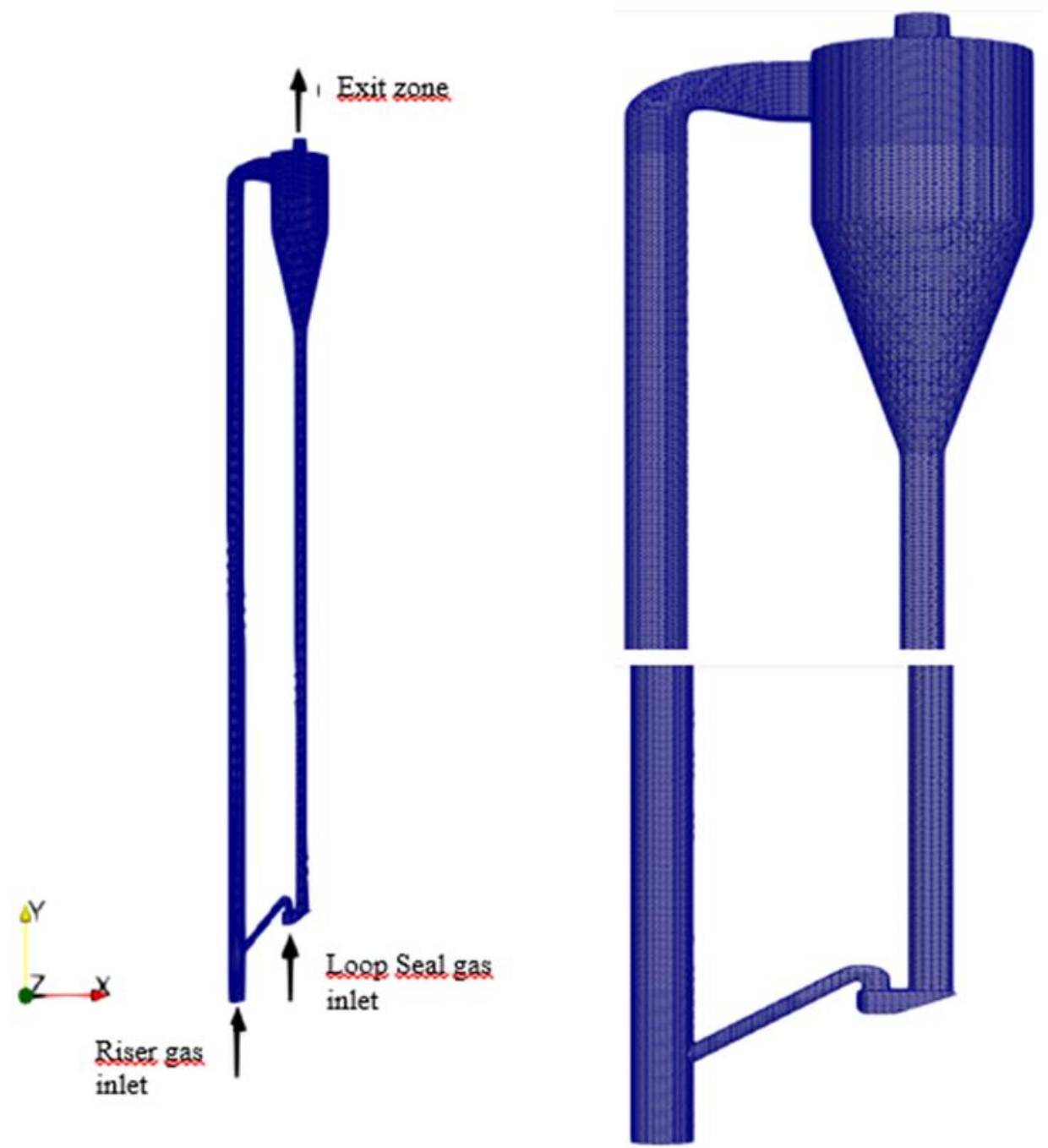

Figure 2. CFB PIC Simulation Grid Cells 
Table 1. Parameters Used in Simulation

\begin{tabular}{|c|c|}
\hline Parameters & Data \\
\hline Riser Diameter D (m) & 0.10 \\
\hline Riser Height H (m) & 5.75 \\
\hline \multicolumn{2}{|l|}{ Gas Phase } \\
\hline Average molecular weight of gas Mavg (kg/kgmol) & 29.0 \\
\hline Viscosity $\mu \mathrm{g}$ (Pa.s) & $1.80 \times 10-5$ \\
\hline Density pg kg/m3 & 1.204 \\
\hline \multicolumn{2}{|l|}{ Solid Phase } \\
\hline Particle diameter $\mathrm{dp}(\mu \mathrm{m})$ & 530 \\
\hline Particle density $\rho s(\mathrm{~kg} / \mathrm{m} 3)$ & 2500 \\
\hline Statistical weight (particle per parcel), np & 100 \\
\hline \multicolumn{2}{|l|}{ PIC Parameters } \\
\hline Solid volume fraction at close pack, $\varepsilon c p$ & 0.55 \\
\hline Volume fraction exponential scale factor & 3.0 \\
\hline Empirical dampening factor & 0.85 \\
\hline Non-singularity constant & $1.0 \times 10-7$ \\
\hline Time step interval & $1.0 \times 10-7-1.0 \times 10-2$ \\
\hline CFD initial time step, $\Delta t(s)$ & $1.0 \times 10-4$ \\
\hline Simulation time, $\mathrm{t}(\mathrm{s})$ & 10 \\
\hline Maximum number of iterations & 500 \\
\hline Time step factor & 0.9 \\
\hline \multicolumn{2}{|l|}{ Solid-Wall Interaction Parameters } \\
\hline Normal particle-wall restitution coefficient, ew & 0.3 \\
\hline Tangential particle-wall restitution coefficient, e $\tau$ & 0.995 \\
\hline \multicolumn{2}{|l|}{ Initial Conditions } \\
\hline Initial riser bed height $(\mathrm{m})$ & 0.6 \\
\hline Initial loop seal bed height (m) & 0.1 \\
\hline Operating temperature, Top (K) & 293.15 \\
\hline \multicolumn{2}{|l|}{$\begin{array}{l}\text { Bed particle diameter distribution: } 50 \% \text { gas, } 50 \% \\
\text { particle defined in Table } 2 \text {. }\end{array}$} \\
\hline \multicolumn{2}{|l|}{ Boundary Conditions } \\
\hline Wall-Boundary Condition & No-Slip \\
\hline \multicolumn{2}{|l|}{ Primary Air Boundary Condition } \\
\hline Gas volume fraction $(\%)$ : & 1.0 \\
\hline Y-axial superficial gas velocity $(\mathrm{m} / \mathrm{s})$ : & 7.0 \\
\hline Pressure (kPa): & 101.325 \\
\hline \multicolumn{2}{|l|}{ Loop Seal Aeration Air Boundary Condition } \\
\hline Gas volume fraction $(\%)$ & 1.0 \\
\hline Mass flow rate $(\mathrm{kg} / \mathrm{s}):$ & 0.04 \\
\hline Pressure (kPa): & 101.325 \\
\hline \multicolumn{2}{|l|}{ Outlet Boundary Condition } \\
\hline Outlet pressure (kPa): & 101.325 \\
\hline
\end{tabular}


Table 2. Solid Diameter Distribution and Solid Phases Suitable for Average Diameter are Defined

\begin{tabular}{|c|c|}
\hline Diameter $(\mu \mathrm{m})$ & Quantity $(\%)$ \\
\hline 300 & 0.1 \\
\hline 400 & 0.1 \\
\hline 500 & 0.5 \\
\hline 600 & 0.1 \\
\hline 700 & 0.1 \\
\hline 800 & 0.1 \\
\hline
\end{tabular}

In this study, the program was run for a time period of 10 seconds. However, the results from the time until the simulation stability was reached in the modeling were not included in the calculation. Figure 3 represents the average pressure values in the lower region of the bed for each time step. It was observed that the statistical stability required for numerical solution improved after the first 2.5 seconds. Accordingly, the first 4 seconds of solution data are not included in the calculation.

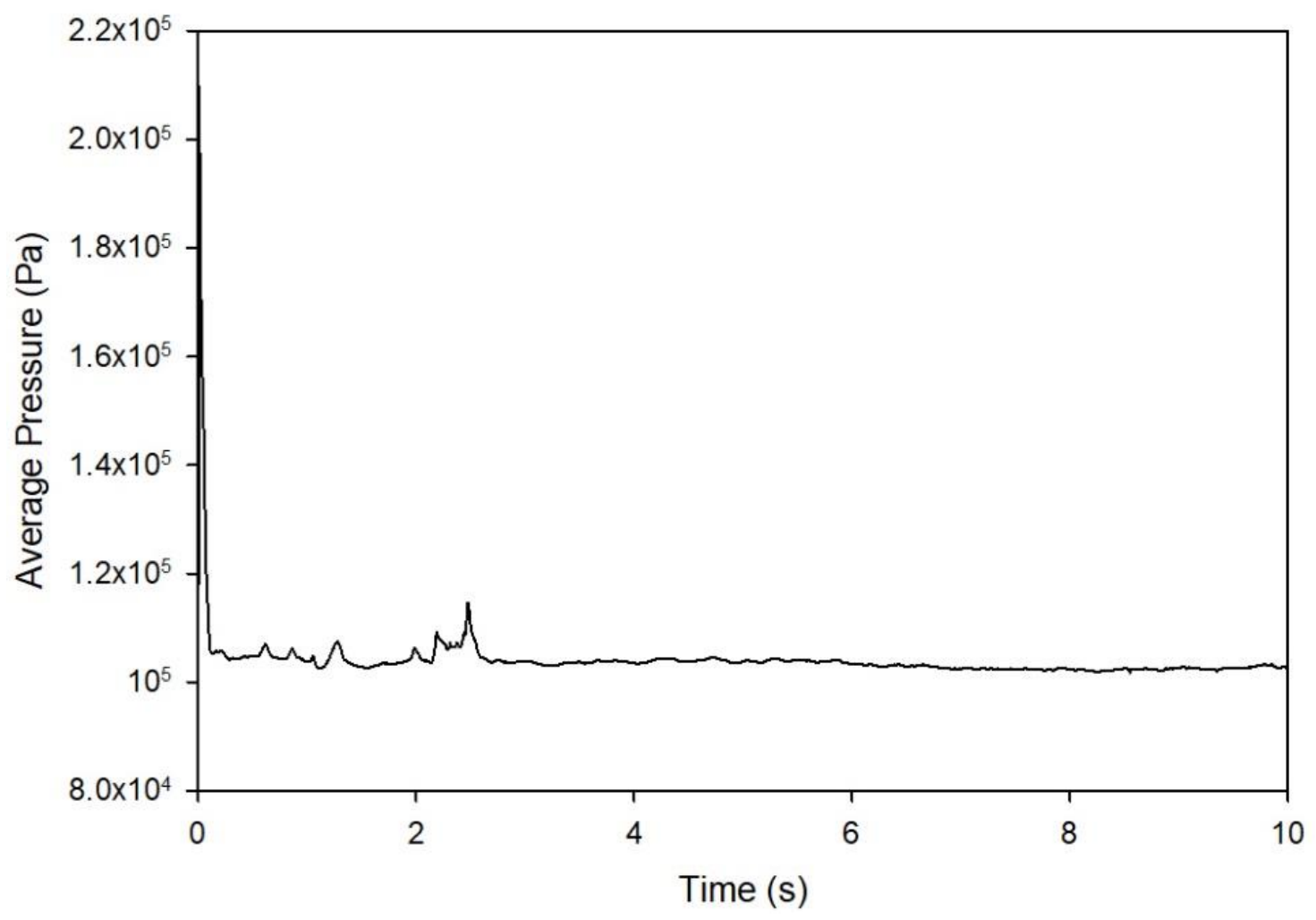

Figure 3 Average Gas Pressure Results of Riser on Time Steps $(H=0.3 m)$

Grid cell size, which is nearly concerned to MP-PIC simulation, is offset by an appropriate grid cell size setting of estimation accuracy and computational cost [50].In the PIC studies in the literature, it was seen that the lattice cell sizes of 20-30 times the particle diameter confirmed the solution. Therefore, a lattice cell size close to the solutions in the literature was chosen. It is given in Table 3. 
Table 3. Grid Analysis

\begin{tabular}{|l|l|}
\hline Condition & Fine grid \\
\hline Cell number & 854,400 \\
\hline Grid size $(\Delta \mathrm{x} \times \Delta \mathrm{y} \times \Delta \mathrm{z})$ & $1.24 \times 1.28 \times 1.27$ \\
\hline Parcel Number (Cell Number/ Statistical weight $\mathrm{np})$ & 85,440 \\
\hline
\end{tabular}

\subsection{Modeling Results}

In this section, the numerical results of the MFiX-PIC have been discussed.

While model validation; pressure graph, particle concentrations, and velocity distributions were taken into consideration and compared with the studies in the literature. Although there are changes in the numerical values depending on the parameters, the graphical shape and the distributions in the velocity contour are among the methods used for model verification in the literature.

The U-shape resemblance of the radial solid distribution and axial solid velocity, as seen in Figure 9b, is an important result for fluid bed modeling validation.

Models of gas-solid systems

Hydrodynamics structure of gas-solid in CFBs are depend on the macroscopic properties, especially gas velocity, pressure distribution, particle velocity, particle concentration (Wang et al., 2017a).

Figure 4 shows the time motion of particles variation in bed at $U g=7.0 \mathrm{~m} / \mathrm{s}$. Solids are at first collected in the loop seal and riser. With the gas coming from the distributor, the solids begin to move from the column lower part to the upper part. Then the particles head into the cyclone with a superficial gas velocity of $7 \mathrm{~m} / \mathrm{s}$. Thanks to the geometric configuration of the cyclone, the particles separate from the gas solid phases and move towards the fall pipe. Gas particles which come from loop seal are carried back to main column. Thus, the cycle of particles in the bed is completed. Also, gas-solid flows change temporarily in the CFB amplifier. The solid phase height in the loop seal decreases as time increases. After 6 seconds solid phase height remains constant, indicating that the system has reached an equilibrium phase.

Figure 5 shows that a snap of the solid fraction of CFB at $\mathrm{Ug}=7.0 \mathrm{~m} / \mathrm{s}$. Particles in the lower region of the riser accumulate in this region initially, and then the particle distribution increases with excessive gas-solid momentum exchange.

Figure 6 shows the distribution of solids and gas in the CFB at $\mathrm{Ug}=7.0 \mathrm{~m} / \mathrm{s}$ and the variation of particle and gas in the bed and cyclone from the top view.

The ascending particles accumulate above the riser, which is the riser upper zone, where there are strong collisions between the ascending particles and falling back particles. The particles irregular characteristics distribution can be seen in different riser zones.

This could be attributed to the distribution of unstable motion of particles through interphase and interactions of inter-particle in the main coloum. The gas flow affected due to wall confinement bend to push through the center zone of the amplifier (Luo et al., 2015; Shi et al., 2015; Wang et al., 2017b). So, a dilute distribution of ascending particles and intense falling particles are monitored in the middle and wall regions of the bed, resulting in an "annular flow" structure typical of flow model inside main coloum (bed column). 
Also, as gas-solid flows are fully developed, the particle back mix close the wall slowly weakens throughout height of the main bed. Solids is based on to the helical motion of the gas phase. As shown in Figure 7, the gas phase entering the cyclone in a tangential direction rotates around the inner surface of the cyclone.

Because of reduction of the conic part, the gas phase moves back and moves axially centerline, eventually leaving a vortex finder. The outer vortex and inner vortex were found to have the same rotational direction for the cyclone, according to the experimental parameters (Wu et al., 2018). Moreover, the estimate outcomes for the CFB with MFIX-PIC method in this study are compatible with the studies which used the CFD-DEM in the literature (Luo et al., 2015; Ma et al., 2017; Wang et al., 2014a, b; Wu et al., 2018). In short applying MFIX-PIC in a pilot scale CFB in order to understand hydrodynamic structure is acceptable.

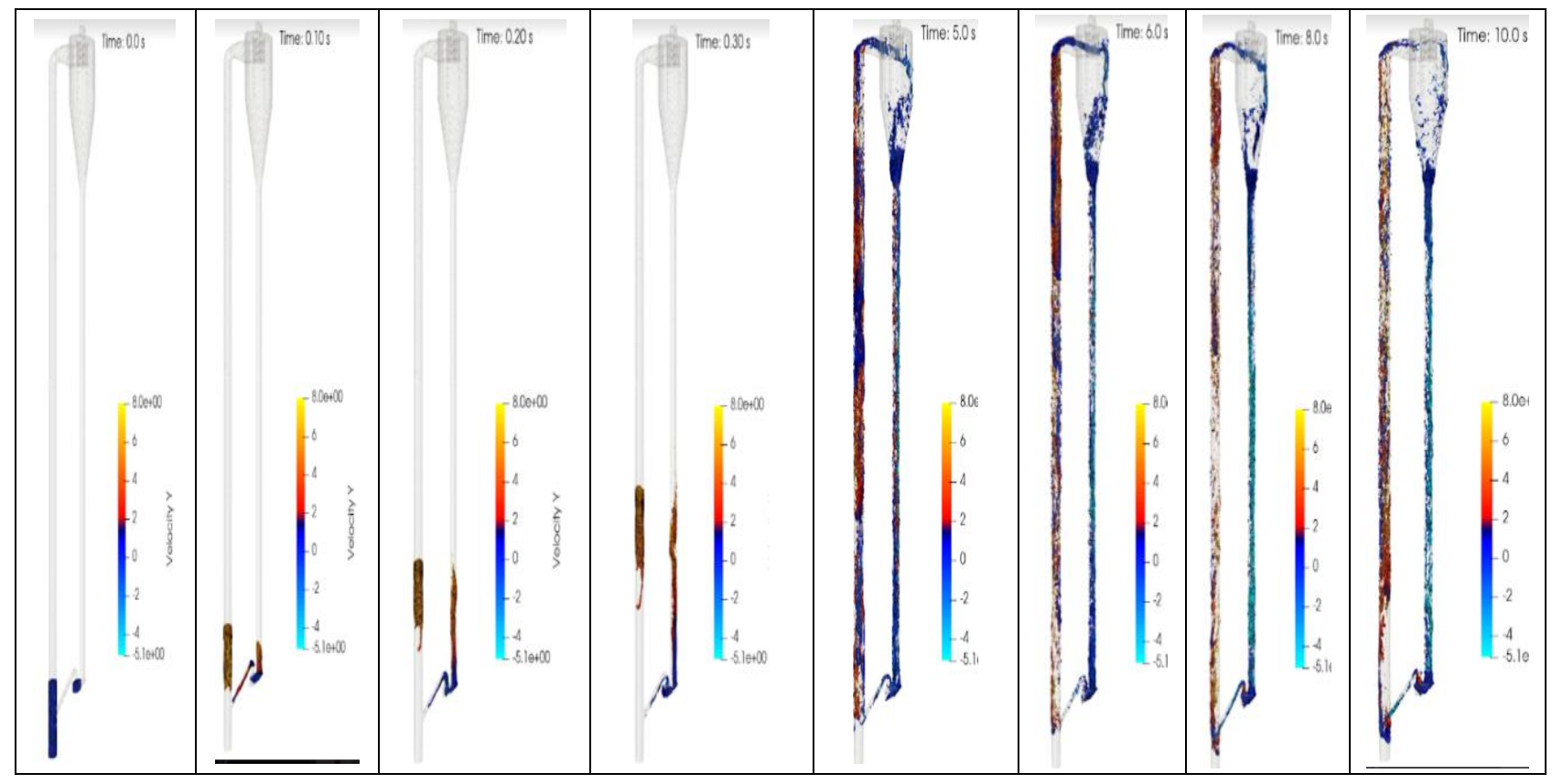

Figure 4. Fluctuation of the Motion of the Particles in the CFB Versus Time $U g=7.0 \mathrm{~m} / \mathrm{s}$
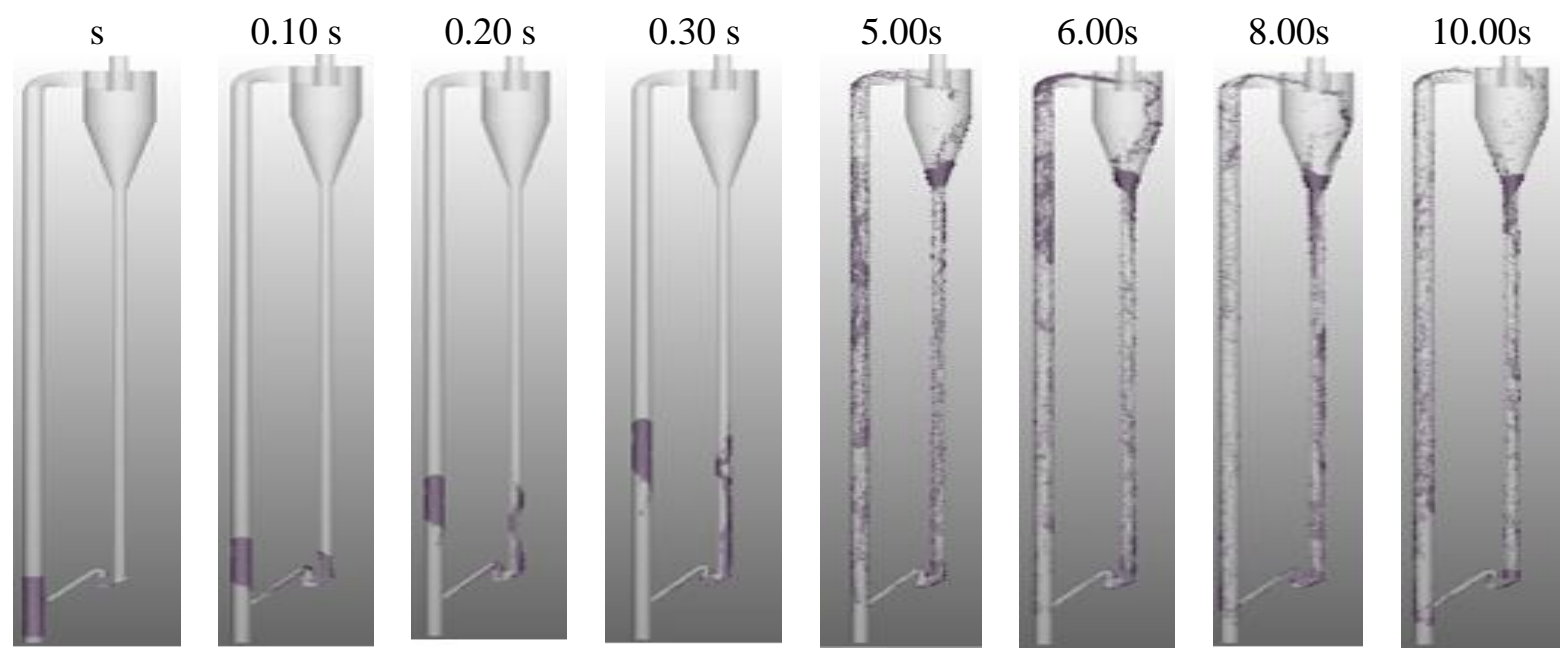

Figure 5 Changes of Solid Distributions Over Time in a Circulating Fluidized Bed Gasifier Ug=7.0 m/s 


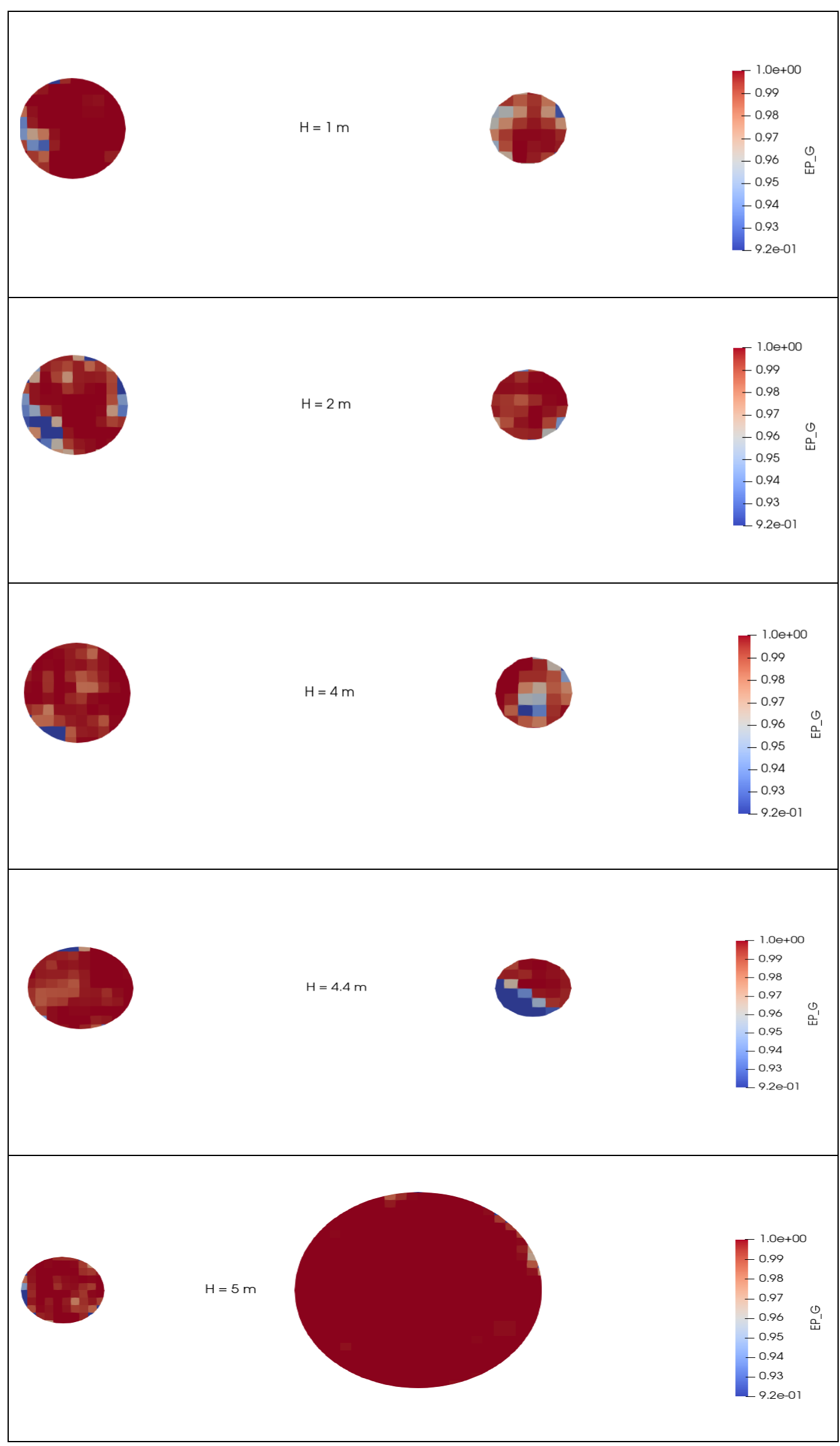

Figure 6. Snapshot Variance of Particles and Gas in the Riser, $t=10 \mathrm{~s}, U g=7.0 \mathrm{~m} / \mathrm{s}$ Solid and Gas Fraction of CFB with Respect to Column Height 


\section{Riser and cyclone solid circulation simulation}

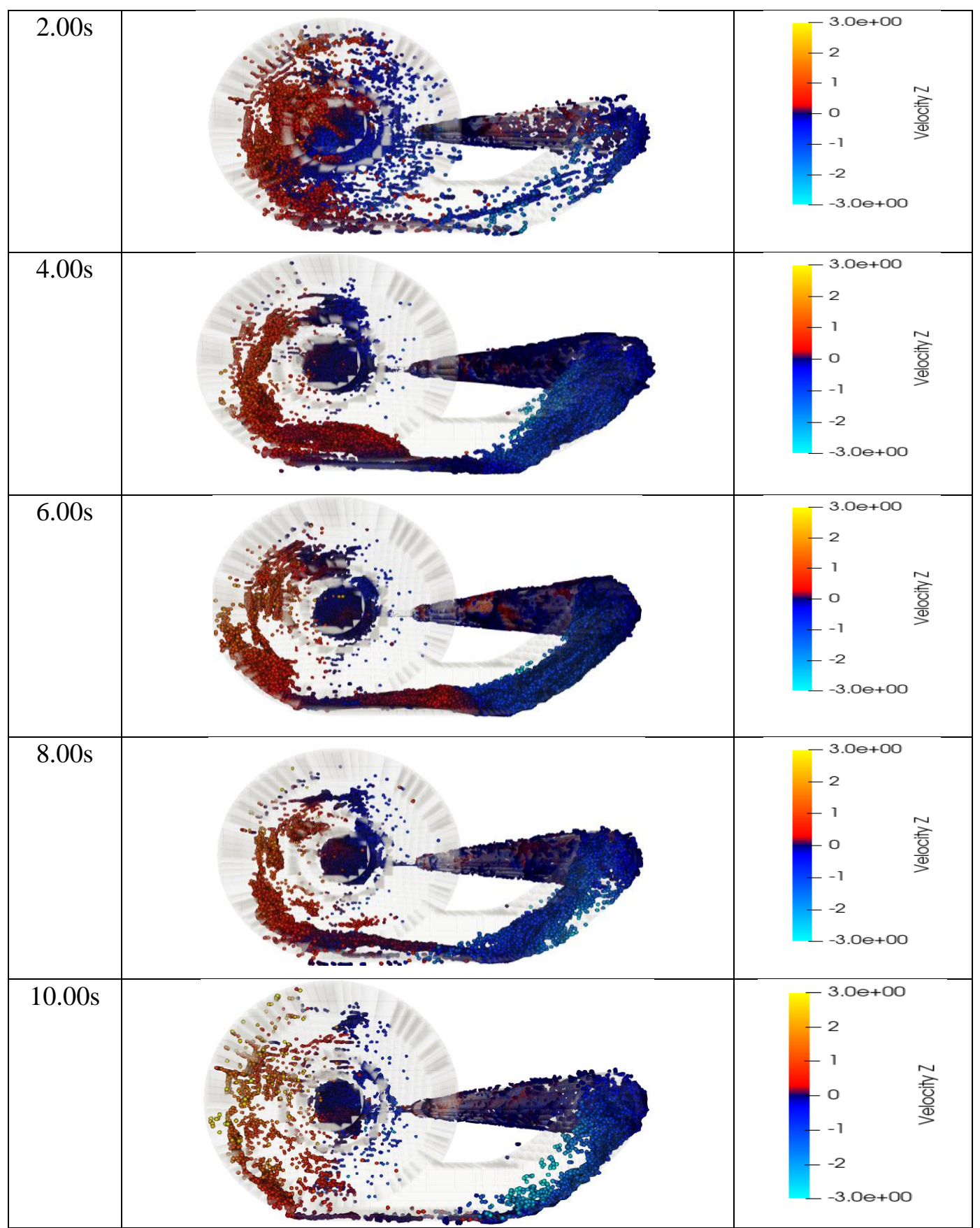

Figure 7. Distribution of Solid Phase Velocity $(\mathrm{Vz})$ in the Bed and Cyclone, $t=10 \mathrm{~s}, U g=7.0 \mathrm{~m} / \mathrm{s}$

\section{Solid behaviour}

Besides that the abrupt movements of the solid distribution, the solid hold up along the column height given in Figure 8 is shown as reported by Topal, 1999; Atimtay \& Topal, 2004.

A large concentration of solids is concerned especially in side of lower zone of the riser and loop seal.

In addition, solid collect close column wall and on riser upper zone (Figure 8a). Throughout the riser height (Figure $8 \mathrm{~b}$ ), the solid distribution on the amplifier under several operational conditions provides a C-type distribution model suitable for experimental measurement (Jiradilok et al., 2008) and numerical prediction (Chen et al., 2017). 


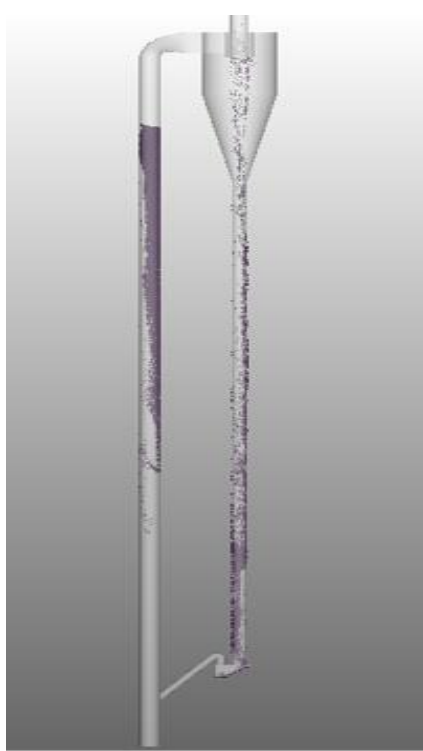

(a)

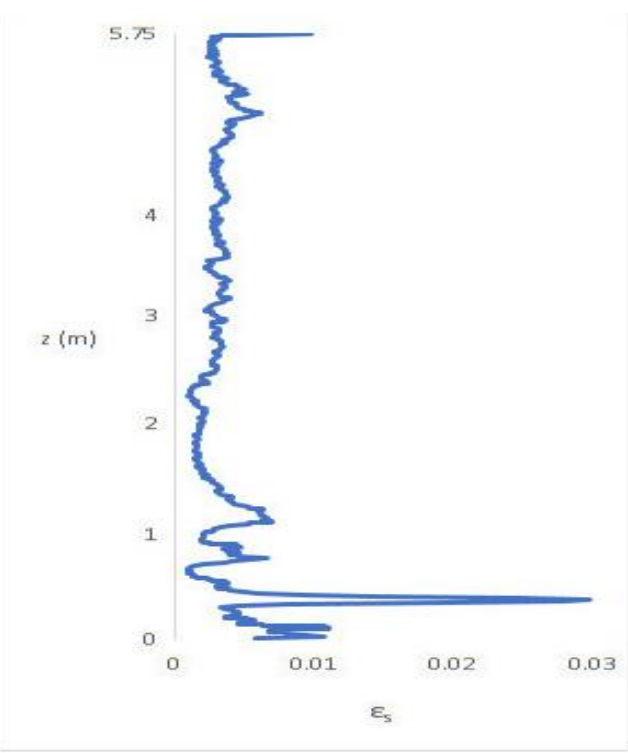

(b)

Figure 8. Solid Volume Fraction of Gasifier, a) Instantaneous Snapshot of Solid Volume Fraction, b) Time-Averaged Solid Volume Fraction Along Center-Line of Riser

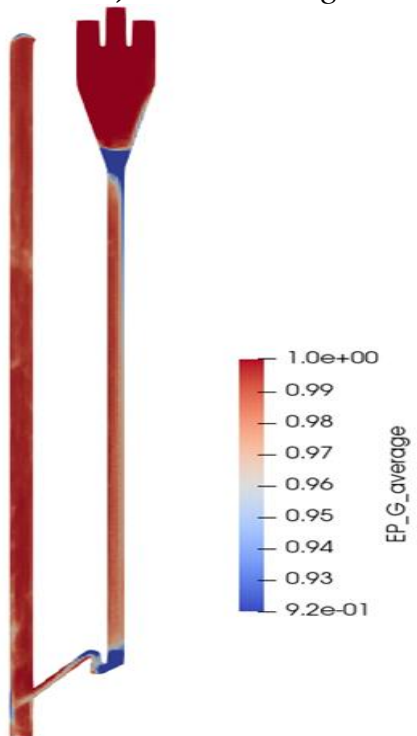

(a)

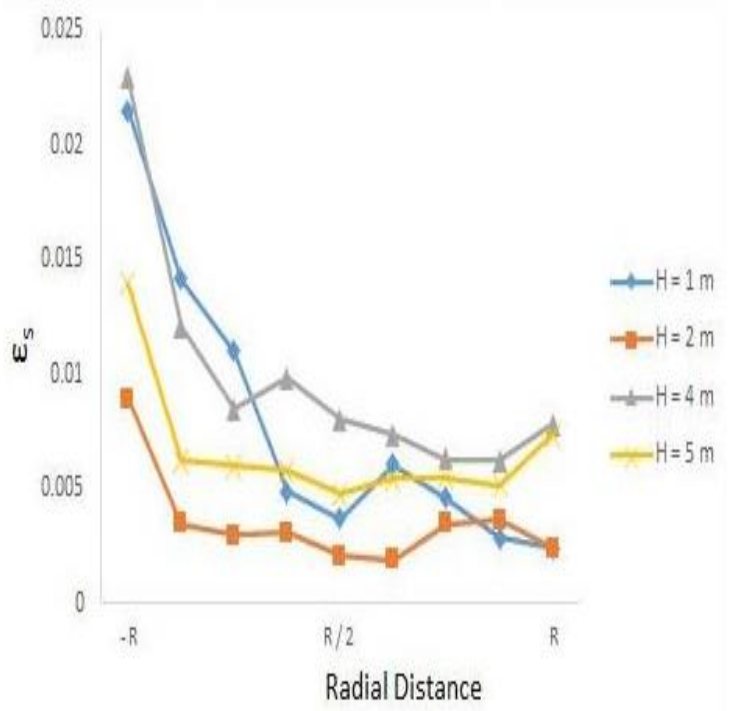

(b)

Figure 9. Gas Distribution Inside of CFB:

a) $U g=7.0 \mathrm{~m} / \mathrm{s}$, b) Radial Profiles Versus Solid Fraction According to the Height of Riser

The dense solids concentration in the lower and upper regions depends on the input and output characteristics of the amplifier. As mentioned in the literature (Bai et al., 1992; Zhou et al., 1994), the bed column solids concentration in the radial direction varies from 0.005 to 0.1 independent of the column height, specifying that solids concentration evaluated by the MFIX-PIC model is appropriate. Also, as superficial gas velocity increases, on the contrary, the particle concentration slowly reduces, based on rised gas phase friction force on the increasing solids.

Figure 9 shows the variation profiles along the radial direction of the solids density occurring at several heights of the main column. The solids density is great close the wall but very low inside the middle region of the riser. In this case, the CFB amplifier also shows the core ring structure. Also, the particle concentration for different heights along the radial axis is not symmetrical due to unidirectional feeding. 
Figure 10 shows that time averaged velocity contours of gas phase and comparison with Yang \& Wang (2020). Gas velocity is decreased in near the wall because of gas-wall interaction. This situation in axial gas velocity can be shown as the reason for the formation of U-shape solid distribution as in Figure 9. The fact that the axial gas velocity slows down towards the walls also causes the solid velocities to slow down, as given in Verma \& Padding (2020).

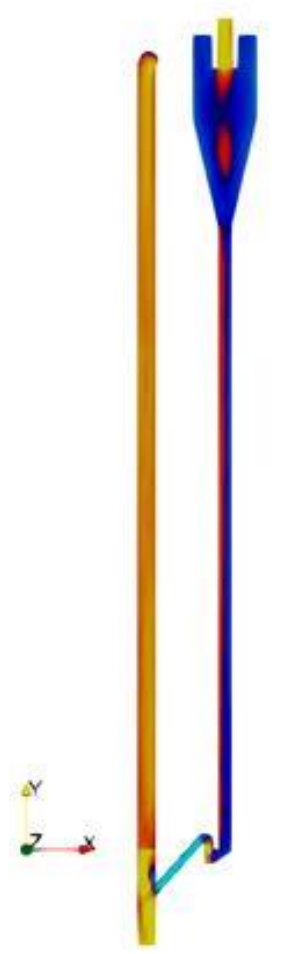

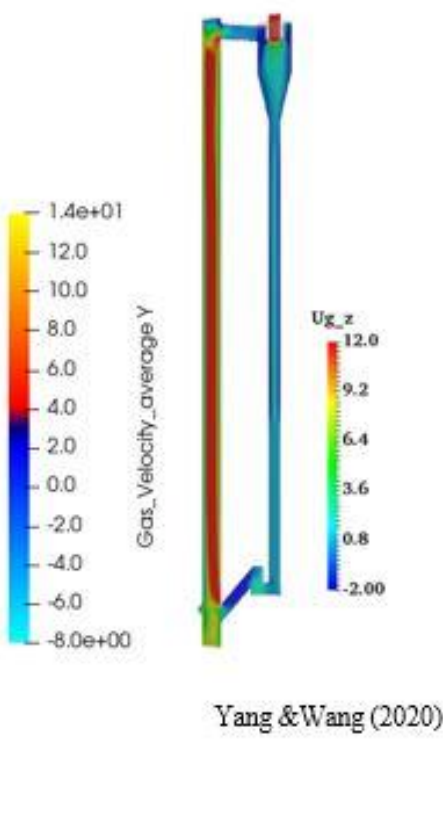

(a)

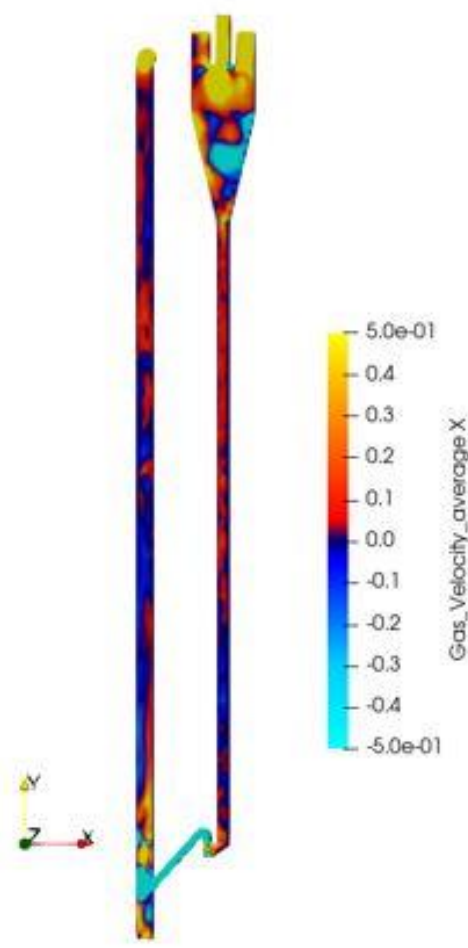

(b)

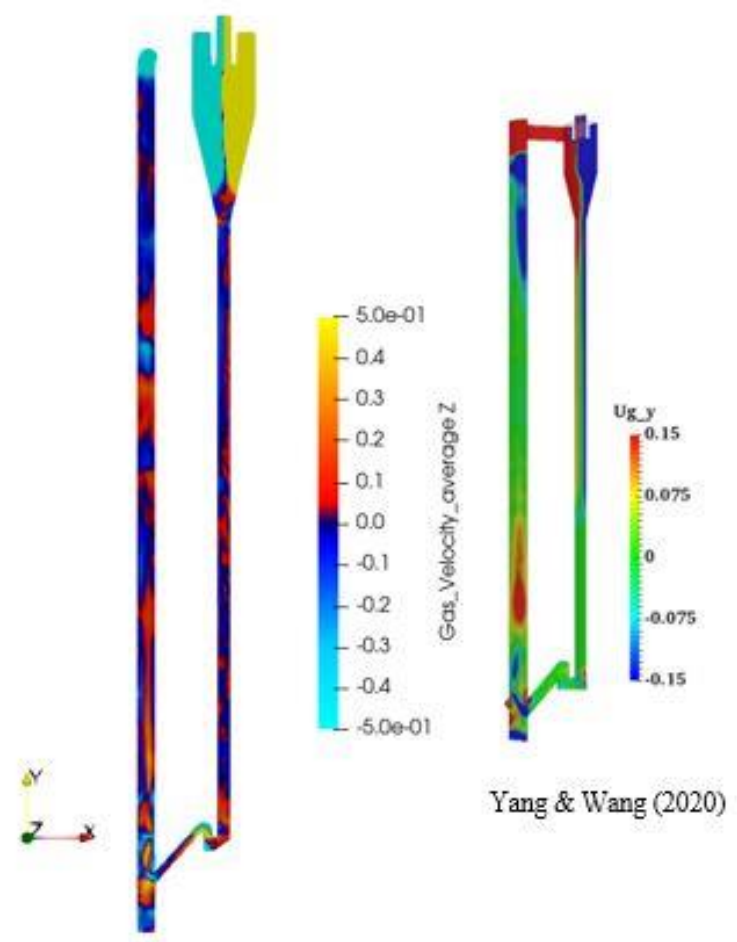

(c)

Figure 10. Time-Averaged Velocity Contours of CFB Gasifier and Comparison with Yang \& Wang (2020) a) $z$-direction, $\boldsymbol{b}) x$-direction, $\boldsymbol{c}$ ) y-direction 
When the z-direction gas velocity distribution in Figure 10c is examined, the structure of cyclone movement has been observed. As expected in the literature and theory, counter-directional velocity distribution in the cyclone region and deceleration towards the middle region of the cyclone were observed.

One way of correcting and symmetrical distribution of gas/solid flows in the bed is to perform a double feed (Wang et al., 2017b). In literature review, the results of the gas/solid flow simulation study conducted by Wang and Yang (2020) and the model outputs obtained from this study are compatible with each other. Meanwhile, our results for solid concentration distributions were also reported by Yang \& Wang (2020) is consistent with their study.

\section{CONCLUSIONS AND DISCUSSIONS}

In this study, MFIX-PIC modeling method was used to determine the gas solid hydrodynamic structure which is basis of gasification in a circulating fluidized bed. In the circulating type fluidized bed model, the movements, solid concentration and velocity distributions of the solid particles in the column cyclone and return line were determined. Based on the numerical results obtained as a result of the modeling, the following conclusions were reached.

(1) Particles drop with a dense concentration close the riser wall, yet despite having a lower concentration, they increase significantly from the riser annular region, explaining as unique "core annulus" flowing model in the main column. Meanwhile, upward solids were monitored moving reverse and forth to the direction of radial aspect of the amplifier

(2) The variation of solid concentrations in the riser depends on the structural characteristics of the riser. However, although solids concentrations in the radial direction vary depending on the column height, generally vary slightly between 0.005 and 0.1 as indicated in the literature; this indicates that the particle concentration estimated by the existing MFIX-PIC simulation method is convenient.

(3) A large concentration of solids is noted in the loop seal and in the lower zone of the bed column.

(4) In addition, particles gather close the barrier together with the upper zone of the main column (Figure 7a). Alongside the riser height (Figure 7b), the particle concentration in the riser under several operational case presents a C-type dispersion model that is appropriate for experimental measurements (Jiradilok et al., 2008) as well as numerical estimation (Chen et al., 2017).

In summary, this study shows that the MP-PIC method gives acceptable results in modelling gas-solid hydrodynamics structure in 3D CFBs and can be used to determine the most basic operating parameters such as empty column gas velocity and bed material selection as well, which should be used in the design and process of CFBs shows.

Axial solid void fraction showed good agreement with the correlations of Yang \& Wang (2020). Their study has mean error value which was calculated as $4 \%$. The mean error value of this study showed as similar as the result of Yang \& Wang (2020).

\section{CONFLICTS OF INTEREST}

The authors declare no conflict of interest.

\section{REFERENCES}

Alobaid, F. (2015). An offset-method for Euler-Lagrange approach. Chemical Engineering Science, 138, 173193. doi: $10.1016 / j . c e s .2015 .08 .010$

Andrews, M. J., \& O'Rourke, P. J. (1996). The multiphase particle-in-cell (MP-PIC) method for dense particulate flows. International Journal of Multiphase Flow, 22(2), 379-402. doi:10.1016/0301$\underline{9322(95) 00072-0}$ 
Auzerais, F. M., Jackson, R., \& Russel, W. B. (1988). The resolution of shocks and the effects of compressible sediments in transient settling. Journal of Fluid Mechanics, 195, 437-462. doi: $10.1017 /$ S0022112088002472

Bai, D. R., Jin, Y., Yu, Z. Q., \& Zhu, J. X. (1992). The axial distribution of the cross-sectionally averaged voidage in fast fluidized beds. Powder Technology, 71(1), 51-58. doi:10.1016/0032-5910(92)88003-Z

Chen, J., Meng, C., Wang, S., Yu, G., Hu, T., \& Lin, F. (2017). Effect of solid mass flux on anisotropic gassolid flowin risers determined with an LES-SOM model. Particuology, 34, 70-80. doi:10.1016/j.partic.2016.12.003

Clarke, M., \& Musser, J. (2020). The MFIX Particle-in-Cell Method (MFIXPIC) Theory Guide; DOE/NETL2020/2115; NETL Technical Report Series; U.S. Department of Energy, National Energy Technology Laboratory: Morgantown, WV, 28. doi:10.2172/1630414

Cundall, P. A., \& Strack, O. D. L. (1979). A discrete numerical model for granular assemblies, Geotechnique, 29(1), 47-65. doi:10.1680/geot.1979.29.1.47

Deen, N. G., Van Sint Annaland, M., Van der Hoef, M. A., \& Kuipers, J. A. M. (2007). Review of discrete particle modeling of fluidized beds. Chemical Engineering Science, 62(1-2), 28-44. doi:10.1016/j.ces.2006.08.014

Ding, J., \& Gidaspow, D. (1990) A bubbling fluidization model using kinetic theory of granular flow. AIChE Journal, 36(4), 523-538. doi:10.1002/aic.690360404

Ergun, S. (1952) Fluid flow through packed columns. Chemical Engineering Progress, 48(2), 89-94.

Gu, J., Shao, Y., Liu, X., Zhong, W. \& Yu, A. (2018). Modelling of particle flow in a dual circulation fluidized bed by a Eulerian-Lagrangian approach. Chemical Engineering Science, 192, 619-633. doi:10.1016/j.ces.2018.08.008

Gidaspow, D. (1994). Multiphase Flow and Fluidization: Continuum and Kinetic Theory Descriptions. Academic Press

Hamidouche, Z., Masi, E., Fede, P., Simonin, O., Mayer, K., \& Penthor, S. (2019). Unsteady three-dimensional theoretical model and numerical simulation of a $120-\mathrm{kW}$ chemical looping combustion pilot plant. Chemical Engineering Science, 193, 102-119. doi:10.1016/j.ces.2018.08.032

Hu, C., Luo, K., Wang, S., Sun, L., \& Fan, J. (2019). Influences of operating parameters on the fluidized bed coal gasification process: A coarse-grained CFD-DEM study. Chemical Engineering Science, 95, 693-706.

Jiang, Y., Qiu, G., \& Wang, H. (2014). Modelling and experimental investigation of the full-loop gas-solid flow in a circulating fluidized bed with six cyclone separators. Chemical Engineering Science, 109, 85-97. doi: $10.1016 /$ j.ces.2014.01.029

Jiradilok, V., Gidaspow, D., Breault, R. W., Shadle, L. J., Guenther, C., \& Shi, S. (2008). Computation of turbulence and dispersion of cork in the NETL riser. Chemical Engineering Science, 63(8), 2135-2148. doi:10.1016/j.ces.2008.01.019

Kallio, S., Peltola, J., \& Niemi T. (2015) Analysis of the time-averaged gas-solid drag force based on data from transient 3D CFD simulations of fluidized beds, Powder Technology, 274, 227-238. doi:10.1016/j.powtec.2015.01.029

Kunii, D., \& Levenspiel, O. (1991). Fluidization Engineering. Butterworth-Heinemann Inc.

Liu, H., Cattolica, R. J., Seiser, R., \& Liao, C-h., (2015). Three-dimensional full-loop simulation of a dual fluidized-bed biomass gasifier. Applied Energy, 160, 489-501. doi:10.1016/j.apenergy.2015.09.065

Liu, H., Cattolica, R. J., \& Seiser, R. (2017). Operating parameter effects on the solids circulation rate in the CFD simulation of a dual fluidized-bed gasification system. Chemical Engineering Science, 169, 235-245. doi:10.1016/j.ces.2016.11.040

Liu, D., \& van Wachem, B. (2019). Comprehensive assessment of the accuracy of CFD- DEM simulations of bubbling fluidized beds. Powder Technology, 343, 145-158. doi:10.1016/j.powtec.2018.11.025 
Lu, L., Gao, X., Shahnam, M., \& Rogers, W. A. (2019). Coarse grained computational fluid dynamic simulation of sands and biomass fluidization with a hybrid drag. AIChE Journal, 66(4), e16867. doi:10.1002/aic.16867

Luo, K., Wu, F., Yang, S., Fang, M., \& Fan, J. (2015). High-fidelity simulation of the 3-D full-loop gas-solid flow characteristics in the circulating fluidized bed. Chemical Engineering Science, 123, 22-38. doi: $\underline{10.1016 / j . c e s .2014 .10 .039}$

Ma, Q., Lei, F., Xu, X., \& Xiao, Y. (2017). Three-dimensional full-loop simulation of a high-density CFB with standpipe aeration experiments. Powder Technology, 320, 574-585. doi:10.1016/j.powtec.2017.07.094

Mokhtar, M. A., Kuwagi, K., Takami, T., Hirano, H. \& Horio, M. (2012). Validation of the Similar Particle Assembly (SPA) Model for the Fluidization of Geldart's Group A and D Particles. AIChE Journal, 58(1), 8798. doi:10.1002/aic.12568

Bierwisch, C., Kraft, T., Riedel, H., \& Moseler, M. (2009). Three-dimensional discrete element models for the granular statics and dynamics of powders in cavity filling. Journal of the Mechanics and Physics of Solids, 57(1), 10-31. doi:10.1016/j.jmps.2008.10.006

Nikolopoulos, A., Nikolopoulos, N., Charitos, A., Grammelis, P., Kakaras, E., Bidwe, A. R. \& Varela, G. (2013). High-resolution 3-D full-loop simulation of a CFB carbonator cold model. Chemical Engineering Science, 90, 137-150. doi:10.1016/j.ces.2012.12.007

O'Rourke, P. J., Zhao, P., \& Snider, D. (2009). A model for collisional exchange in gas/liquid/solid fluidized beds. Chemical Engineering Science, 64(8), 1784-1797. doi:10.1016/j.ces.2008.12.014

O'Rourke, P. J., \& Snider, D. M. (2010). An improved collision damping time for MP-PIC calculations of dense particle flows with applications to polydisperse sedimenting beds and colliding particle jets. Chemical Engineering Science, 65(22), 6014-6028. doi:10.1016/j.ces.2010.08.032

O'Rourke, P. J., \& Snider, D. M. (2012). Inclusion of collisional return-to-isotropy in the MP-PIC method. Chemical Engineering Science, 80, 39-54. doi:10.1016/j.ces.2012.05.047

O'Rourke, P. J., \& Snider, D. M. (2014). New blended acceleration model for the particle contact forces induced by an interstitial fluid in dense particle/fluid flows. Powder Technology, 256, 39-51. doi:10.1016/j.powtec.2014.01.084

Patankar N. A., \& Joseph D. D. (2001). Modeling and numerical simulation of particulate flows by the Eulerian-Lagrangian approach. International Journal of Multiphase Flow, 27(10), 1659-1684. doi:10.1016/S0301-9322(01)00021-0

Sakai, M., \& Koshizuka, S. (2009). Large-scale discrete element modeling in pneumatic conveying. Chemical Engineering Science, 64(3), 533-539. doi:10.1016/j.ces.2008.10.003

Shi, X., Sun, R., Lan, X., Liu, F., Zhang, Y., \& Gao, J. (2015). CPFD simulation of solids residence time and back-mixing in CFB risers. Powder Technology, 271, 16-25. doi:10.1016/j.powtec.2014.11.011

Snider, D. M. (2001). An Incompressible Three-Dimensional Multiphase Particle-in-Cell Model for Dense Particle Flows. Journal of Computational Physics, 170(2), 523-549. doi:10.1006/jcph.2001.6747

Squires, A. M. (1982). Contribution towards a history of fluidization. In: Proceeding of the Joint Meeting of Chemical Engineering Society of China and AIChE, 322-353.

Stroh, A., Daikeler, A., Nikku, M., May, J., Alobaid, F., von Bohnstein, M., Ströhle, J., \& Epple, B. (2019). Coarse grain 3D CFD-DEM simulation and validation with capacitance probe measurements in a circulating fluidized bed. Chemical Engineering Science, 196, 37-53. doi:10.1016/j.ces.2018.11.052

Tsuji, Y., Kawaguchi, T., \& Tanaka, T. (1993). Discrete particle simulation of two-dimensional fluidized bed. Powder Technology, 77(1), 79-87. doi:10.1016/0032-5910(93)85010-7

Thapa, R. K., Frohner, A., Tondl, G., Pfeifer, C., \& Halvorsen, B. M. (2016). Circulating fluidized bed combustion reactor: Computational Particle Fluid Dynamic model validation and gas feed position optimization. Computers \& Chemical Engineering, 92, 180-188. doi:10.1016/j.compchemeng.2016.05.008 
Topal, H. (1999). Experimental Investigation of Hydrodynamic, Combustion and Emission Properties of Circulating Fluidized Bed. PhD Thesis, Gazi University, Ankara, Turkey. (In Turkish).

Atimtay, A. T. \& Topal, H. (2004). Co-combustion of olive cake with lignite coal in a circulating fluidized bed. Fuel, 83(7-8), 859-867. doi:10.1016/j.fuel.2003.09.015

Wang, Q., Yang, H., Wang, P., Lu, J., Liu, Q., Zhang, H., Wei, L., \& Zhang, M. (2014a). Application of CPFD method in the simulation of a circulating fluidized bed with a loop seal, part I-determination of modeling parameters, Powder Technol. 253, 814-821. doi:10.1016/j.powtec.2013.11.041

Wang, Q., Yang, H., Wang, P., Lu, J., Liu, Q., Zhang, H., Wei, L., \& Zhang, M. (2014b). Application of CPFD method in the simulation of a circulating fluidized bed with a loop seal part II-investigation of solids circulation. Powder Technology, 253, 822-828. doi:10.1016/j.powtec.2013.11.040

Wang, S., Lu, H., Zhao, F., \& Liu, G. (2014). CFD studies of dual circulating fluidized bed reactors for chemical looping combustion processes. Chemical Engineering Journal, 236, 121-130. doi: $10.1016 /$ j.cej.2013.09.033

Wang, Q., Niemi, T., Peltola, J., Kallio, S., Yang, H., Lu, J., \& Wei, L. (2015). Particle size distribution in CPFD modeling of gas-solid flows in a CFB riser. Particuology, 21, 107-117. doi:10.1016/j.partic.2014.06.009

Wang, S., Luo, K., Yang, S., Hu, C., \& Fan, J. (2017a) LES-DEM investigation of the time-related solid phase properties and improvements of flow uniformity in a dual-side refeed CFB. Chemical Engineering Journal, 313, 858-872. doi:10.1016/j.cej.2016.10.130

Wang, S., Luo, K., Hu, C., \& Fan, J. (2017b). CFD-DEM study of the effect of cyclone arrangements on the gas-solid flow dynamics in the full-loop circulating fluidized bed. Chemical Engineering Science, 172, 199215. doi:10.1016/j.ces.2017.05.052

Wang, S., Luo, K., Hu, C., Sun, L., \& Fan, J. (2018). Effect of superficial gas velocity on solid behaviors in a full-loop CFB. Powder Technology, 333, 91-105. doi:10.1016/j.powtec.2018.04.011

Wen, C. Y., \& Yu, Y. H. (1966). Mechanics of fluidization. The Chemical Engineering Progress Symposium Series, 162, 100-111.

Wu, Y., Peng, L. Qin, L., Wang, M., Gao, J., \& Lan, X. (2018). Validation and application of CPFD models in simulating hydrodynamics and reactions in riser reactor with Geldart A particles. Powder Technology, 323, 269-283. doi:10.1016/j.powtec.2017.10.003

Xu, Y., Musser, J., Li, T., Gopalan, B., Panday, R., Tucker, J., Breault, G., Clarke, M. A., \& Rogers, W. A. (2018). Numerical simulation and experimental study of the gas-solid flow behavior inside a full-loop circulating fluidized bed: evaluation of different drag models. Ind. Eng. Chem. Res., 57(2), 740-750. doi:10.1021/acs.iecr.7b03817

Verma, V. \& Padding, J. T. (2020). A novel approach to MP-PIC: Continuum particle model for dense particle flows in fluidized beds. Chemical Engineering Science: X, 6, 100053. doi:10.1016/j.cesx.2019.100053

Verma, V., Padding, J. T., Deen, N. G., \& Kuipers, J. A. M. (2015). Effect of bed size on hydrodynamics in 3-D gas-solid fluidized beds. AIChE Journal, 61(5), 1492-1506. doi:10.1002/aic.14738

Yang, S., Wang, S., Luo, K., Fan, J., \& Chew, J. W. (2019). Numerical investigation of the backmixing and non-uniform characteristics in the three-dimensional full-loop circulating fluidized bed combustor with six parallel cyclones. Applied Thermal Engineering, 153, 524-535. doi:10.1016/j.applthermaleng.2019.03.032

Yang, S., \& Wang, S. (2020). Eulerian-Langrangian simulation of the full-loop gas-solid hydrodynamics in a pilot-scale circulating fluidized bed. Powder Technology, 369, 223-237. doi:10.1016/j.powtec.2020.05.043

Zhang, N., Lu, B., Wang, W., \& Li, J. (2010). 3D CFD simulation of hydrodynamics of a 150MWe circulating fluidized bed boiler. Chemical Engineering Journal, 162(2), 821-828. doi:10.1016/j.cej.2010.06.033

Zhang, Y., Zhao, Y., Lu, L., Ge, W., Wang, J., \& Duan, C. (2017) Assessment of polydisperse drag models for the size segregation in a bubbling fluidized bed using discrete particle method. Chemical Engineering Science, 160, 106-112. doi:10.1016/j.ces.2016.11.028 
Zhong, W., Yu, A., Zhou, G., Xie, J., \& Zhang, H. (2016). CFD simulation of dense particulate reaction system: approaches, recent advances and applications. Chemical Engineering Science, 140, 16-43. doi: $10.1016 / j . c e s .2015 .09 .035$

Zhou, J., Grace, J. R., Qin, S., Brereton, C. M. H., Lim, C. J., \& Zhu, J. (1994). Voidage profiles in a circulating fluidized bed of square cross-section. Chemical Engineering Science, 49(19), 3217-3226. doi:10.1016/00092509(94)E0125-A 